\title{
Constraints on the formation of Yakutian eclogites derived from the crystal chemistry of iron in clinopyroxene and garnet
}

\author{
C. McCammon ${ }^{1}$, M. Longo ${ }^{1}$, F. Nestola ${ }^{2}$, T. Boffa-Ballaran ${ }^{1}$, N. Ross ${ }^{3}$, H. O’Neill ${ }^{4}$ \\ ${ }^{1}$ Bayerisches Geoinstitut, Univ. Bayreuth, Germany \\ ${ }^{2}$ Dipartimento di Geoscienze, Univ. Padova, Italy \\ ${ }^{3}$ Dept. of Geological Sciences, Virginia Tech, Blacksburg VA, USA \\ ${ }^{4}$ Research School of Earth Sciences, ANU, Canberra ACT, Australia
}

Clinopyroxene (cpx) and garnet are well known for their ability to incorporate large amounts of water (e.g., Bell and Rossmann, 1992). However systematic studies of the water content in these minerals have shown that the lowest concentrations are typically found in samples from the highest pressure regions, i.e., in diamond-bearing eclogite xenoliths (e.g., Matsyuk et al., 1998; Koch-Müller at al., 2004). Whether or not these low water concentrations indeed reflect conditions during eclogite formation, however, depends on factors such as the nature of hydrogen incorporation in the structures and how easily it is lost. Motivated by the importance (and challenge) of quantifying the nature of volatiles during eclogite formation, we are undertaking a systematic study of a suite of eclogite xenoliths from kimberlites to correlate major element concentrations, structural parameters, iron oxidation states, and hydrogen concentrations, in order to assess the degree to which these parameters were preserved during exhumation, and hence determine the likely conditions under which the eclogites were formed.

The sample suite comprised nine handpicked separates of unaltered cpx and garnet extracted from eclogite xenoliths (some diamondiferous) from the Zagadochnaya and the Udachnaya kimberlites, both in the Yakutia craton (Russia). In the first stage of the study we collected single crystal X-ray diffraction data for each cpx sample, and made full structure refinements incorporating constraints from chemical analyses (electron microprobe) and iron oxidation state (Mössbauer spectroscopy). Further details of the procedure and results from the refinements are given in Nestola et al. (2007), and show that three of the samples (U947, Ud2290, and 90-394) have a significant number of vacancies on cation sites.

We focus on cpx U947 which contains the largest number of cation vacancies $(0.051$ per 6 oxygen atoms). Various studies have reported a correlation for omphacitic cpx between cation vacancies and hydrogen content (Fig. 1); hence we measured the hydrogen concentration of cpx U947 using Fourier-transform infrared (FTIR) spectroscopy. The water content was

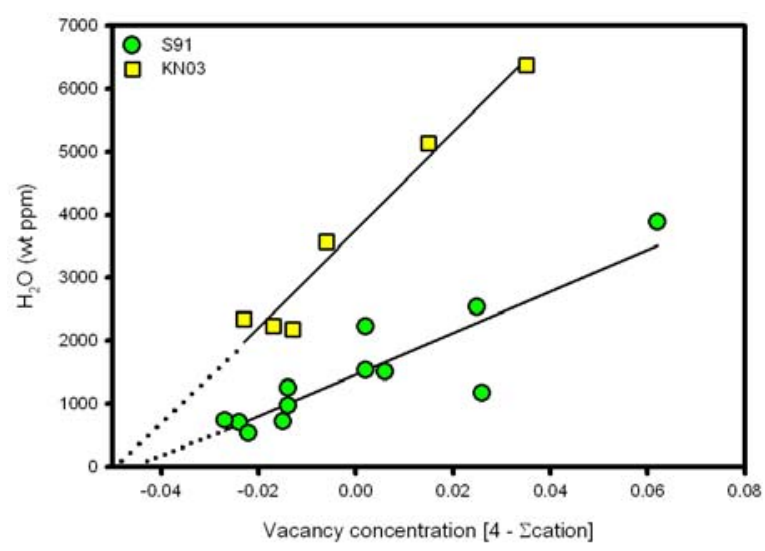

Fig. 1. Variation of cation vacancy with $\mathrm{H}_{2} \mathrm{O}$ concentration in omphacitic cpx according to data reported by Smyth et al. (1991) (S91) and Katayama and Nakashima (2003) (KN03).

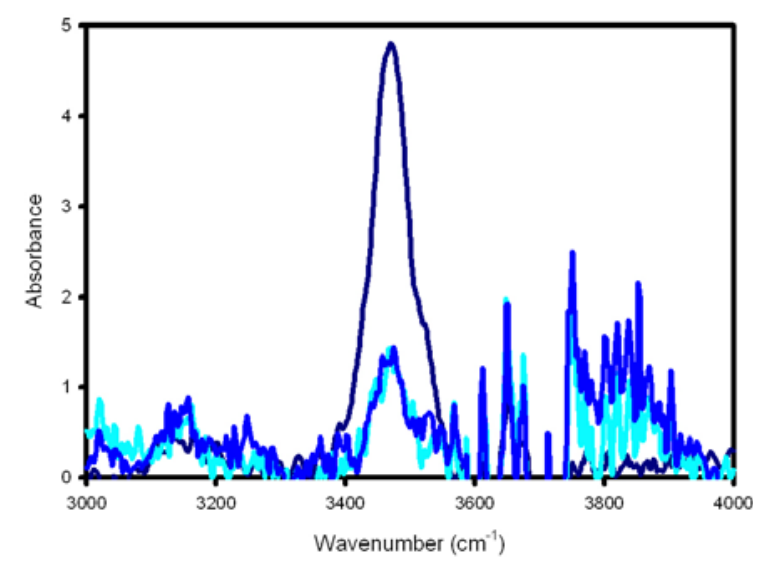

Fig. 2. Polarised FTIR spectrum of cpx U947 indicating absorbance for the three principal directions.

derived from integral absorbances measured by taking polarized spectra with the electrical field vector parallel to the three axes of the indicatrix. Only one band was seen with maximum absorption parallel to $\gamma$, as is usual for omphacites (Skogby, 2006) (Fig. 2). The total $\mathrm{H}_{2} \mathrm{O}$ content was determined to be 89 ppm (wt) using the integral extinction coefficient reported by Bell et al. (1995). This value is clearly less than predicted by Fig. 1, raising the possibility that hydrogen was lost during exhumation. 
The most likely dehydrogenation mechanism is

$\mathrm{Fe}^{2+}+\mathrm{OH}^{-} \rightarrow \mathrm{Fe}^{3+}+\mathrm{O}^{2-}+1 / 2 \mathrm{H}_{2}$

(e.g., Ingrin and Skogby, 2000); hence we can use the $\mathrm{Fe}^{3+}$ concentration to determine the maximum amount of hydrogen that could have been lost. We used a new method to determine accurate site occupancies of cpx by collecting Mössbauer spectra at multiple temperatures and fitting them simultaneously with centre shift constraints based on the second-order Doppler shift and area constraints based on differences in recoil-free fraction (Fig. 3). Based on the observed $\mathrm{Fe}^{3+} / \Sigma \mathrm{Fe}$ value of $15.8 \%$, we calculate that the maximum amount of water that could have been lost according to reaction (1) is $380 \mathrm{ppm}$, which is significantly less than the amount predicted by Fig. 1. The cation vacancies are therefore stabilised by a different mechanism than hydrogen incorporation.

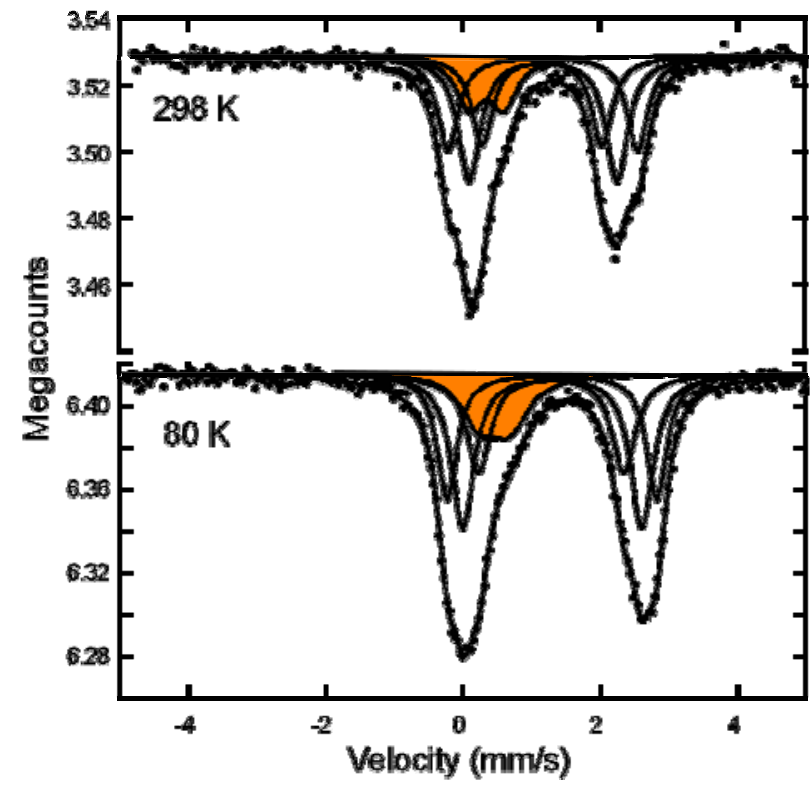

Fig. 3. Mössbauer spectra of cpx U947 at two different temperatures. The spectra were fit simultaneously using interspectrum centre shift and area constraints based on the temperature of data collection. $\mathrm{Fe}^{3+}$ absorption is indicated in red and constitutes $15.8 \%$ of the area.

Laboratory experiments have shown that nonstoichiometric clinopyroxene can be stabilised under nominally anhydrous conditions at both high pressure (Wood and Henderson, 1978; Gasparik, 1986) and ambient pressure (Okui et al., 1998), where charge balance is achieved primarily through substitution of $\mathrm{Al}^{3+}$ for $\mathrm{Mg}^{2+}$ on the $\mathrm{M} 1$ site and causes a contraction of the M1 site volume compared to stoichiometric clinopyroxenes with the same composition (Oberti and Caporuscio, 1991). The structure data from sample U947 shows a similar trend (Fig. 1 in Nestola et al., 2007); hence we conclude that the high vacancy concentration in cpx $\mathrm{U} 947$ is stabilised by $\mathrm{Al}^{3+}$ substitution for $\mathrm{Mg}^{2+}$ on the M1 site to maintain charge balance, and did not involve significant hydrogen substitution in the structure.
Before we can conclude that water fugacity was low during the last equilibration conditions of sample U947, however, there are other factors which must be considered (e.g., Matsyuk et al., 1998). These include the solubility of water in co-existing phases and the relevant partition coefficients. To assess these factors, we first need to estimate the $\mathrm{P}, \mathrm{T}$ conditions under which sample U947 last equilibrated. These are calculated to be $978^{\circ} \mathrm{C}$ and $3 \mathrm{GPa}$ based on $\mathrm{Fe} / \mathrm{Mg}$ exchange between garnet and cpx (Ellis and Green, 1979) and the observation that Udachnaya sample U947 contains no diamond. At these P,T conditions the solubility of water in omphacitic cpx is significantly higher than our observed value of 89 ppm (e.g., KochMüller et al., 2004), and similarly the solubility of water in pyrope is also higher (Lu and Keppler, 1997). Although water has long been known to be incompatible during mantle melting processes (reviewed by Kohn and Grant, 2006), the temperature of last equilibration is too low for partial melting. We therefore conclude that sample U947 indeed equilibrated under conditions of low water fugacity, although not necessarily in the absence of a fluid.

We can calculate the composition of a C-O-H fluid in equilibrium with the eclogite assemblage at these $\mathrm{P}, \mathrm{T}$ conditions using the approach outlined by Holloway (1987) based on the equations of state by Belonoshko and Saxena (1992). We used the EXCEL spreadsheet described by Huizenga (1985) with fugacity coefficients calculated using the Fortran program SUPERFLUID (Belonoshko et al., 1992) and assumed carbon activity to be 1.0 .

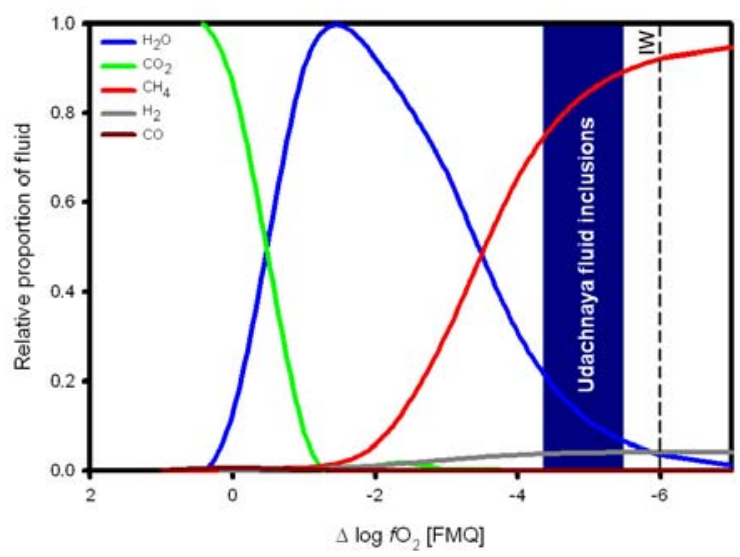

Fig. 4. Fluid speciation as a function of oxygen fugacity relative to the fayalite-magnetite-quartz (FMQ) buffer at $3 \mathrm{GPa}$ and $978^{\circ} \mathrm{C}$, corresponding to the last equilibration conditions of sample U947. The shaded region indicates the corresponding oxygen fugacity range determined for fluid inclusions from garnet xenoliths in Udachnaya kimberlite by Tomilenko et al. (1997). IW indicates the iron-wüstite buffer.

The results (Fig. 4) show a strong dependence of fluid composition on oxygen fugacity, in accordance with many previous calculations (e.g., Wood et al., 1990), and show that the mole fraction of $\mathrm{H}_{2} \mathrm{O}$ decreases strongly with decreasing oxygen fugacity. It is therefore tempting to speculate that sample U947 
equilibrated under conditions of low oxygen fugacity, no more than 2-3 log bar units above the iron-wüstite (IW) buffer. This low oxygen fugacity is consistent with the relatively low $\mathrm{Fe}^{3+} / \Sigma \mathrm{Fe}$ values that we found for cpx $(15.8 \%)$ and garnet $(2.9 \%)$ compared to typical mantle values (McCammon, 2005). The conclusion that oxygen fugacity was low is also supported by a detailed study of fluid inclusions in natural and synthetic diamonds as well as garnets from mantlederived xenoliths in kimberlite pipes of Yakutia that concluded based on compositional data and thermodynamic modelling that oxygen fugacities were similarly low, no more than two log bar units above IW (Tomilenko et al., 1997).

\section{Acknowledgments}

We are grateful to R. Rudnick and Z. Spetsius for supplying the samples, R. Rudowski for skilled hand picking of the mineral separates, H. Keppler for the FTIR measurements, and A. Belonoshko for providing a copy of the program SUPERFLUID. We thank H. Schulze for sample preparation and D. Krausse and A. Potzel for collecting the electron microprobe data.

\section{References}

Bell, D.R. and Rossman, G.R., 1992. Water in Earth's mantle: The role of nominally anhydrous minerals. Science, 255: 1391-1397.

Bell, D., Ihinger, P. and Rossman, G., 1995. Quantitative analysis of trace $\mathrm{OH}$ in garnet and pyroxenes. American Mineralogist, 80: 465-474.

Belonoshko, A.B. and Saxena, S.K., 2002. A unified equation of state for fluids of C-H-O-N-S-Ar composition and their mixtures up to very high temperatures and pressures. Geochimica et Cosmochimica Acta, 56: 3611-3626.

Belonoshko, A.B., Shi, P. and Saxena, S.K., 1992. SUPERFLUID: A Fortran-77 program for calculation of Gibbs free energy and volume of C-H-O-N-S-Ar mixtures. Computers \& Geosciences, 18: 1267-1269.

Ellis, D.J. and Green, D.H., 1979. An experimental study of the effect of $\mathrm{Ca}$ upon garnet-clinopyroxene $\mathrm{Fe}-\mathrm{Mg}$ exchange. Contributions to Mineralogy and Petrology, 71: 13-22.

Gasparik, T., 1986. Experimental-study of subsolidus phaserelations and mixing properties of clinopyroxene in the silica-saturated system $\mathrm{CaO}-\mathrm{MgO}-\mathrm{Al}_{2} \mathrm{O}_{3}-\mathrm{SiO}_{2}$. American Mineralogist, 71: 686-693.

Holloway, J.R., 1987. Igneous fluids. In: I.S.E. Carmichael and H.P. Eugster (Editors), Thermodynamic Modeling of Geological Materials: Minerals, Fluids, and Melts. Mineralogical Society of America, Washington DC, pp. 211-233.
Huizenga, J.M., 2005. COH, an Excel spreadsheet for composition calculations in the $\mathrm{C}-\mathrm{O}-\mathrm{H}$ fluid system. Computers \& Geosciences, 31: 797-800.

Ingrin, J. and Skogby, H., 2000. Hydrogen in nominally anhydrous upper-mantle minerals: Concentration levels and implications. European Journal of Mineralogy, 12: 543-570.

Koch-Müller, M., Matsyuk, S.S. and Wirth, R., 2004. Hydroxyl in omphacites and omphacitic clinopyroxenes of upper mantle to lower crustal origin beneath the Siberian platform. American Mineralogist, 89: 921-931.

Kohn, S.C. and Grant, K.J., 2006. The partitioning of water between nominally anhydrous minerals and silicate melts. In: H. Keppler and J.R. Smyth (Editors), Water in Nominally Anhydrous Minerals. Geochemical Society \& Mineralogical Society of America, Chantilly, USA, pp. 231-241.

$\mathrm{Lu}, \mathrm{R}$. and Keppler, H., 1997. Water solubility in pyrope to 100 kbar. Contributions to Mineralogy and Petrology, 129: 35-43.

Matsyuk, S.S., Langer, K. and Hösch, A., 1998. Hydroxyl defects in garnets from mantle xenoliths in kimberlites of the Siberian platform. Contributions to Mineralogy and Petrology, 132: 163-179.

McCammon, C., 2005. Mantle oxidation state and oxygen fugacity: Constraints on mantle chemistry, structure and dynamics. In: R.D.v.d. Hilst, J. Bass, J. Matas and J. Trampert (Editors), Earth's Deep Mantle: Structure, Composition, and Evolution. American Geophysical Union, Washington D.C., pp. 221-242.

Nestola, F., Longo, M., McCammon, C. and Boffa Ballaran, T., 2007. Crystal-structure refinement of Na-bearing clinopyroxenes from mantle-derived eclogite xenoliths. American Mineralogist, 92: 1242-1245.

Oberti, R. and Caporuscio, F., 1991. Crystal chemistry of clinopyroxenes from mantle eclogites: a study of the key role of the M2 site population by means of crystal structure refinement. American Mineralogist, 76: 1141-1152.

Okui, M., Sawada, H. and Marumo, F., 1998. Strcture refinement of a nonstoichiometric pyroxene synthesized under ambient pressure. Physics and Chemistry of Minerals, 25: 318-322.

Skogby, H., 2006. Water in natural mantle minerals I: Pyroxenes. Reviews in Mineralogy and Geochemistry, 62: 155-167.

Tomilenko, A.A., Chepurov, A.I., Pal'yanov, Y.N., Pokhilenko, L.N. and Shebanin, A.P., 1997. Volatile components in the upper mantle (in Russian). Geologiya i Geofizika, 38: 276-285.

Wood, B.J. and Henderson, C.M.B., 1978. Compositions and unit-cell parameters of synthetic non-stoichiometric tschermakitic clinopyroxenes. American Mineralogist, 63: 66-72.

Wood, B.J., Bryndzia, L.T. and Johnson, K.E., 1990. Mantle oxidation state and its relationship to tectonic environment and fluid speciation. Science, 248: 337345. 